\title{
Is vitamin $D$ status a determining factor for metabolic syndrome? A case-control study
}

This article was published in the following Dove Press journal:

Diabetes, Metabolic Syndrome and Obesity:Targets and Therapy 9 June 2011

Number of times this article has been viewed

\section{Shabnam Salekzamani \\ Tirang R Neyestani \\ Hamid Alavi-Majd \\ Anahita Houshiarrad \\ Ali Kalayi \\ Nastaran Shariatzadeh \\ A'azam Gharavi}

Department of Nutrition Research, National Research Institute and

Faculty of Nutrition and Food Technology, Shahid Beheshti University of Medical Sciences, Tehran, Iran
Correspondence: Tirang R Neyestani Laboratory of Nutrition Research, National Nutrition and Food Technology Research Institute (NNFTRI), Shahid Beheshti University of Medical Sciences, Tehran, 1981619573, Iran

Tel +98 2I 2237647 I

Fax +98 21 22360660

Email t.neyestani@nnftri.ac.ir
Abstract: This study was undertaken to assess vitamin D status in nonmenopausal women with metabolic syndrome (MeS) and to evaluate its possible role in inflammation and other components of MeS. A case-control study was conducted during late fall and winter 2009-10. A total of 375 women with waist circumference $(\mathrm{WC}) \geq 88 \mathrm{~cm}$ were examined to find 100 who met MeS criteria according to the National Cholesterol Education Program (NCEP)/Adult Treatment Panel (ATP) III criteria (NCEP/ATP III). Of those without MeS, 100 age- and residence area-matched women were selected as a control group. Anthropometric and laboratory evaluations were performed. Waist-to-hip ratio (WHR), body mass index (BMI), homeostatic model of insulin resistance (HOMA-IR) and body fat mass (FM) were also evaluated. Women with MeS had significantly higher BMI, waist circumference (WC) and FM but lower serum osteocalcin than controls. There was no significant difference in serum 25 hydroxyvitamin D $(25[\mathrm{OH}] \mathrm{D})$, intact parathyroid hormone (iPTH) or vitamin D status between the two groups. Serum highly sensitive C-reactive protein (hSCRP) concentration was significantly higher in the MeS group, compared to the controls $(3.4 \pm 3.3$ vs $2.0 \pm 1.9 \mathrm{mg} / \mathrm{L}, P<0.001)$. The difference remained significant even after controlling for BMI $(P=0.011)$, WC $(P=0.014)$ and FM $(P=0.005)$. When comparison was made only in those subjects with insulin resistance (HOMA-IR > 2.4), hsCRP was still higher in the MeS group $(\mathrm{n}=79)$ than in the control group $(\mathrm{n}=61)(P<0.001)$. When data were categorized according to vitamin $\mathrm{D}$ status, in the MeS group significantly higher plasma glucose concentrations were observed in subjects with vitamin D deficiency compared to those with insufficiency or sufficiency $(104.0 \pm 11.7,83.0 \pm 11.3$ and $83.2 \pm 9.9 \mathrm{mg} / \mathrm{dL}$, respectively, $P<0.001$ ). Interestingly, their WC or WHR did not show any significant difference. In stepwise regression analysis, 25(OH)D was the main predictor of both hsCRP and plasma glucose. Vitamin D status may, at least in part, be a determining factor of systemic inflammation and the related metabolic derangements of MeS.

Keywords: metabolic syndrome, vitamin D, inflammation

\section{Introduction}

Metabolic syndrome (MeS) is characterized by several abnormalities including impaired glucose tolerance, blood lipid derangements, and prothrombotic and pro-inflammatory states. ${ }^{1}$ A number of studies have suggested abdominal obesity as the major culprit in $\mathrm{MeS} .{ }^{2}$ It is believed that visceral fat, by secreting some inflammatory adipokines, brings about both insulin resistance and an inflammatory state. ${ }^{3}$ Elevated blood inflammatory biomarkers such as C-reactive protein (CRP), interleukin (IL)-6, IL-18 and tumor necrosis factor (TNF)- $\alpha$ have been found in individuals with MeS. ${ }^{4}$ Body fat mass (FM) and waist circumference (WC) have been found to be predictors of circulating highly sensitive C-reactive protein (hsCRP) in Iranian middle-aged women. ${ }^{5}$ Fat distribution seems 
to have a crucial role in the development of further metabolic disturbances. It has been shown that, unlike abdominal adiposity, gluteofemoral fat can be protective against metabolic derangements. ${ }^{6}$

Extra fat deposition in the body, depending on its location, can adversely affect vitamin D status. Adipose tissue has been shown to act as a "metabolic well" for vitamin D, hence reducing its bioavailability. ${ }^{7} \mathrm{New}$ studies support an inverse association between vitamin $\mathrm{D}$ status and insulin resistance, MeS and type 2 diabetes (T2D). ${ }^{8,9} \mathrm{~A}$ possible role for vitamin $\mathrm{D}$ deficiency in the pathogenesis of MeS has been recently proposed. ${ }^{10,11}$ Circulating 25 hydroxyvitamin D $(25[\mathrm{OH}] \mathrm{D})$ has been inversely associated with abdominal adiposity, hypertriglyceridemia, and hyperglycemia. ${ }^{12}$ Vitamin D status may indirectly affect MeS development. Low serum osteocalcin, a vitamin D-dependent Gla-protein, ${ }^{13}$ has been recently reported in subjects with MeS. ${ }^{14,15}$

The immune-modulatory effect of vitamin $\mathrm{D}$ and its inverse link with inflammation ${ }^{16}$ draws more attention to its possible role in MeS. Obesity and MeS are usually accompanied by "low-grade systemic inflammation"17 and augmented oxidative stress, ${ }^{18}$ both of which are believed to have pivotal roles in development of MeS itself and in its further morbidities. ${ }^{19}$ It has been recently reported that even with the same body mass index (BMI), subjects with higher circulating inflammatory markers such as interleukin (IL)-6 are more likely to have insulin resistance. ${ }^{20}$ Low vitamin D status has been linked to inflammatory endothelial dysfunction in both diabetic and nondiabetic subjects. ${ }^{21,22}$ The oxidative-stress attenuating effect of vitamin $\mathrm{D}$ is a new finding that has been related to its anticancer effect. ${ }^{23}$ However, some other studies indicated that $1,25(\mathrm{OH}) 2 \mathrm{D}$ enhances inflammatory reaction in both human and murine adipocyte culture medium. ${ }^{24}$

In this study it was hypothesized that in the presence of high WC, vitamin D status is a contributing factor in MeS. To examine this hypothesis, a case-control study was conducted on nonmenopausal women residing in Tehran to: a) compare vitamin D status between subjects with and without $\mathrm{MeS}$; b) determine the relationship between circulating $25(\mathrm{OH}) \mathrm{D}$ and the components of MeS; and c) examine the relationship between $25(\mathrm{OH}) \mathrm{D}$ and certain oxidative stress and inflammatory biomarkers.

\section{Subjects and methods Study design}

This was a case-control study performed during the fall and winter, 2009-2010. Considering the higher prevalence of obesity and MeS in women than in men in $\operatorname{Iran}^{25}$ and the possible effects of menopause on the metabolism of bone and calcitropic hormones, only nonmenopausal women were studied in this research project. On the first visit, full information on the study design and objectives were given to all subjects in a face-to-face interview before they signed a written informed consent. A general questionnaire on demographic data and duration of direct sun exposure, based on recalled usual number of minutes/hours spent in daylight, was also completed. Duration of daily sun exposure was categorized as less than 10 minutes, 10 minutes to 1 hour, 1-2 hours and more than 2 hours. ${ }^{26}$ Then, blood pressure was measured and subjects were requested to return after an overnight (12-14 hours) fast for blood sampling. In this study, MeS was defined according to the National Cholesterol Education Program (NCEP)/Adult Treatment Panel (ATP) III criteria. ${ }^{1}$ The scientific and ethical issues of this study were approved by the Research Council and the Ethical Committee of the National Nutrition and Food Technology Research Institute (NNFTRI), respectively.

\section{Subjects}

To find 100 women with MeS, 375 women with abdominal obesity from health centers and school staffs from Tehran were examined. The inclusion criteria were: 1) willingness to participate; 2 ) aged $30-50$ years; 3 ) being nonmenopausal; 4) waist circumference $\geq 88 \mathrm{~cm} ; 5$ ) absence of any clinical disease; 6) not being pregnant or lactating; and 7) not receiving any nutritional supplement for at least 3 months preceding the study. This latter criterion was actually found necessary because irregular supplement use was common and impossible to quantify accurately. Women who met three out of five criteria of NCEP/ATP III (including high WC), were identified as having $\mathrm{MeS}$ and allocated to the cases group. Of the remaining subjects, 100 age- and residence regionmatched women were selected as a control group.

\section{Anthropometry and blood pressure}

Weight was measured with light clothes and without shoes to the nearest $0.1 \mathrm{~kg}$ using a digital scale (Seca 840; Seca GmbH, Hamburg, Germany). Height was measured without shoes to the nearest $0.1 \mathrm{~cm}$ with a measuring tape mounted onto the wall. A triangular ruler was put on the top of the subject's head and then the number on the measuring tape at the intercept of the ruler and the tape was considered as the subject's height. BMI was calculated using the equation $\mathrm{BMI}=$ weight $(\mathrm{kg}) /$ height $(\mathrm{m})^{2}$. Hip circumference $(\mathrm{HC})$ and WC were both measured by a measuring tape to the nearest $0.1 \mathrm{~cm}$. WC was determined at the midpoint between the 
lowest rib and iliac crest while the subject was in a standing position and after expiration. Systolic blood pressure (SBP) and diastolic blood pressure (DBP) were measured in a seated position, after a 5-minute rest, using a digital sphygmomanometer (BC08; Beurer GmbH, Ulm, Germany).

\section{Estimation of body fat mass (FM)}

The percentage of body FM was evaluated using a bioelectrical impedance analysis (BIA) system (Quadscan 4000; BodyStat Ltd, Onchan, Isle of Man, UK).

\section{Laboratory investigations}

\section{Blood sample handling}

Venous blood samples collected after 12-14 hours fasting were transferred into two tubes, either with or without the anticoagulant sodium fluoride. Plasma recovered from the anticoagulated blood sample was used to measure glucose and lipids within 2 hours of sample collection. Sera obtained after centrifugation of clotted samples at $1000 \times g$ at room temperature were stored in aliquots at $-80^{\circ} \mathrm{C}$ until the day of analysis.

\section{Glycemic status and lipid profile}

Plasma glucose, triglycerides (TG), total cholesterol, lowdensity lipoprotein cholesterol (LDL-C), and high-density lipoprotein cholesterol (HDL-C) were measured using enzymatic colorimetric methods (all from Pars Azmoon, Tehran, Iran). Serum insulin was determined by immunoradiometric assay (IRMA) using a commercial kit (Biosource Diagnostics, Aartrijke, Belgium) and a gamma-counter system (Gamma I; Genesys, Grand Blanc, MI). Insulin resistance was evaluated by homeostasis model assessment of insulin resistance (HOMA-IR) index calculated using the following equation: ${ }^{27}$

$$
\begin{aligned}
\text { HOMA-IR }= & \text { fasting plasma glucose }(\mathrm{mmol} / \mathrm{L}) \times \text { serum } \\
& \text { insulin }(\mathrm{mU} / \mathrm{L}) / 22.5
\end{aligned}
$$

\section{Inflammatory and oxidative stress biomarkers}

Serum concentrations of hsCRP were measured by immunoturbidometric method (Pars Azmoon, Tehran, Iran) with the aid of an auto-analyzer (Selectra E; Vital Scientific, Spankeren, the Netherlands). Malondialdehyde (MDA) was measured based on thiobarbituric acid reacting substances (TBARS) method as described originally ${ }^{28}$ with some minor modifications..$^{29}$ For measuring total antioxidant capacity (TAC), a colorimetric method with Azino-bis(3-methylb enzothiazolin-6-sulfonic acid) diammonium salt (ABTS) reagent was used. ${ }^{30}$

\section{Circulating $25(\mathrm{OH}) \mathrm{D}$, intact parathyroid} hormone (iPTH) and osteocalcin

Serum 25(OH)D was assayed using high-performance liquid chromatography (HPLC) as described earlier. ${ }^{31}$ In this study, vitamin $\mathrm{D}$ status was defined based on serum concentration of $25(\mathrm{OH}) \mathrm{D}$ as: deficiency $\leq 27.5 \mathrm{nmol} / \mathrm{L}$; insufficiency 27.5 $\leq 25(\mathrm{OH}) \mathrm{D}<50 \mathrm{nmol} / \mathrm{L}$; and sufficiency $\geq 50 \mathrm{nmol} / \mathrm{L}$. ${ }^{32}$ Serum iPTH concentrations were determined using enzymelinked immunosorbant assay (ELISA) kits (DRG Instruments $\mathrm{GmbH}$, Marburg, Germany and Biosource Diagnostics, Aartrijke, Belgium, respectively) and a plate reader (Stat Fax 3200; Awareness Technology Inc, Palm City, FL). The intraand interassay variations for all ELISA tests were less than $5 \%$ and $6 \%$, respectively, as stated by the manufacturers.

\section{Statistical analyses}

Data were expressed as mean \pm standard deviation (SD). For quantitative data, comparison between groups was made using Student's $t$-test. To control confounding factors in comparing data between groups, analysis of covariance was employed. Qualitative data was compared between groups using the Chi square test. Correlations between two sets of data were evaluated using Pearson's equation. To predict the relationship between circulating 25(OH)D and MeS components, stepwise regression analysis was used. All statistical analyses were performed using Statistical Package for Social Sciences (SPSS) (v 16; SPSS Inc, Chicago, IL). In this study $P<0.05$ was considered significant.

\section{Results}

Of the population examined for MeS, 28.3\% met the NCEP/ ATP III criteria. Subjects with MeS had significantly higher BMI, WC and FM. However, there was no significant difference in circulating $25(\mathrm{OH}) \mathrm{D} 3$ or intact parathyroid hormone (iPTH) between groups. Serum osteocalcin, a vitamin D-dependent bone protein, was significantly lower in women with MeS than in the control group (Table 1). The difference remained significant even after controlling for BMI $(P<0.001)$, WC $(P=0.001)$ and FM $(P=0.002)$. Neither duration of sun exposure $\left(\chi^{2}=2.478, P=0.479\right)$ nor vitamin D status (Table 2 ) differed significantly between the two groups. Duration of daily direct sun exposure in $77.2 \%$ of the cases and $72.4 \%$ of the controls was between 10-60 minutes, and in respectively $25 \%$ and $31.6 \%$ was less than 10 minutes. Serum hsCRP concentration was significantly higher in the MeS group, compared to the controls $(P<0.001)$. The difference remained significant even after controlling for BMI $(P=0.011)$, WC $(0.014)$ 
Table I The clinical and biochemical characteristics of study population

\begin{tabular}{|c|c|c|c|}
\hline \multirow[t]{2}{*}{ Variables } & \multicolumn{2}{|l|}{ Groups } & \multirow[t]{2}{*}{$P$-value } \\
\hline & $\begin{array}{l}\text { Case } \\
\text { mean (SD) }\end{array}$ & $\begin{array}{l}\text { Control } \\
\text { mean (SD) }\end{array}$ & \\
\hline Age (years) & $42.0(8.5)$ & $42.3(5.6)$ & 0.79 \\
\hline Weight (kg) & $82.4(11.5)$ & $76.0(11.5)$ & $<0.001$ \\
\hline Height $(\mathrm{cm})$ & I57.7 (6.2) & $158.0(6.0)$ & 0.74 \\
\hline BMI $\left(\mathrm{kg} / \mathrm{m}^{2}\right)$ & $33.1(15.4)$ & $30.4(4.5)$ & $<0.001$ \\
\hline$W C(\mathrm{~cm})$ & I0I.4 (8.2) & $95.7(9.8)$ & $<0.001$ \\
\hline Hip circumference $(\mathrm{cm})$ & 108.I (9.2) & $104.5(7.4)$ & 0.003 \\
\hline WHR & $0.93(0.05)$ & $0.91(0.05)$ & 0.01 \\
\hline FM (\%) & $4 I .6(6.1)$ & $39.7(4.8)$ & 0.02 \\
\hline $\mathrm{SBP}(\mathrm{mmHg})$ & $122.5(16.2)$ & $112.6(12.5)$ & $<0.001$ \\
\hline $\mathrm{DBP}(\mathrm{mmHg})$ & 76.7 (II.3) & $71.4(9.7)$ & $<0.001$ \\
\hline Glucose (mg/dL) & I0I.2 (I3.5) & $91.9(10.0)$ & $<0.001$ \\
\hline TG (mg/dL) & I83.| (74.2) & $104.6(43.3)$ & $<0.001$ \\
\hline Cholesterol (mg/dL) & $194.4(40.2)$ & I70.I (33.5) & $<0.001$ \\
\hline LDL-C (mg/dL) & $105.5(24.3)$ & 91.7 (2I.5) & $<0.001$ \\
\hline HDL-C (mg/dL) & $41.3(9.1)$ & $50.9(9.9)$ & $<0.001$ \\
\hline Insulin $(\mu \mathrm{U} / \mathrm{mL})$ & I7.4 (8.9) & I5.3 (7.5) & 0.07 \\
\hline HOMA-IR & $4.1(2.0)$ & $3.4(1.7)$ & 0.01 \\
\hline $25(\mathrm{OH}) \mathrm{D}(\mathrm{nmol} / \mathrm{L})$ & $16.7(16.4)$ & $13.9(14.1)$ & 0.21 \\
\hline MDA (nmol/L) & $3.7(0.8)$ & $3.9(1.1)$ & 0.19 \\
\hline $\begin{array}{l}\text { TAC (mmol/L of BSA } \\
\text { equivalent) }\end{array}$ & I.4 (0.5) & $\mathrm{I} .3(0.3)$ & 0.06 \\
\hline hsCRP (mg/L) & $3.4(3.3)$ & $2.0(1.9)$ & $<0.001$ \\
\hline iPTH (pg/mL) & $47.3(30.8)$ & $50.2(30.3)$ & 0.572 \\
\hline Osteocalcin (ng/mL) & $0.8(1.5)$ & I.8 (2.6) & 0.002 \\
\hline
\end{tabular}

Abbreviations: BMI, body mass index; BSA, bovine serum albumin; DBP, diastolic blood pressure; FM, fat mass; HDL-C, high-density lipoprotein cholesterol; HOMA-IR, homeostasis model assessment of insulin resistance; hsCRP, highly sensitive C-reactive protein; iPTH, intact parathyroid hormone; LDL-C, low-density lipoprotein cholesterol; MDA, malondialdehyde; SBP, systolic blood pressure; TAC, total antioxidant capacity; TG, triglycerides; WC, waist circumference; WHR, waistto-hip ratio; $25(\mathrm{OH}) \mathrm{D}, 25$-hydroxyvitamin $\mathrm{D}$.

and FM $(P=0.005)$. When comparison was made only in those subjects with insulin resistance (HOMA-IR > 2.4), ${ }^{33}$ hsCRP was still higher in the MeS group $(n=79)$ than in the control group $(\mathrm{n}=61)(P<0.001)$. Serum $25(\mathrm{OH}) \mathrm{D}$ negatively correlated with hsCRP $(r=-0.331, P=0.002)$ and FM ( $r=-0.326, P=0.004)$ in the whole study population. Association between 25(OH)D and hsCRP disappeared after controlling for FM $(r=-0.212, P=0.065)$.

On evaluating the correlations separately in the two groups, $25(\mathrm{OH}) \mathrm{D}$ inversely correlated with hsCRP in women

Table 2 The occurrence of vitamin D deficiency in women with and without metabolic syndrome

\begin{tabular}{lll}
\hline Vitamin D status & MeS & Control \\
\hline Deficiency & $86(86)$ & $89(89)$ \\
Insufficiency & $9(9)$ & $7(7)$ \\
Sufficiency & $5(5)$ & $4(4)$ \\
\hline
\end{tabular}

Notes: $\chi^{2}=0.850, P=0.654$. with and without $\mathrm{MeS}(r=-0.344, P=0.016$; and $r=-0.357$, $P=0.042$, respectively). However, after controlling for BMI or FM, only in the MeS group did the correlation remain significant $(r=-0.370, P=0.012$ and $r=-0.305, P=0.039$, respectively). Serum MDA and TAC also did not differ significantly between the two groups. Only the MeS group, showed a significant correlation between $25(\mathrm{OH}) \mathrm{D}$ and TAC ( $r=-0.284, P=0.048$ ), which remained significant even after controlling for BMI $(r=-0.335, P=0.026), \mathrm{FM}(r=-0.347$, $P=0.021)$ and $\mathrm{WC}(r=-0.228, P=0.031)$. The association, however, disappeared after controlling for plasma glucose $(r=-0.162, P=0.133)$.

When data were categorized according to vitamin D status, only the MeS subjects with vitamin D deficiency showed significantly higher plasma glucose concentrations as compared to those with vitamin D insufficiency or sufficiency $(104.0 \pm 11.7,83.0 \pm 11.3$ and $83.2 \pm 9.9 \mathrm{mg} / \mathrm{dL}$, respectively, $P<0.001)$. Interestingly, their WC $(100.9 \pm 9.7$, $102.3 \pm 10.2$ and $108.6 \pm 12.2 \mathrm{~cm}$, respectively, $P=0.240)$ or waist-to-hip ratio (WHR) $(0.94 \pm 0.06,0.97 \pm 0.03$ and $0.92 \pm 0.02$, respectively) did not differ significantly. In this group, none of the other MeS components had a significant difference among the categorized subgroups.

In stepwise regression analysis to establish a model to predict hsCRP with the components of MeS as independent variables, two models were obtained in which WC was the only predictor in both $\mathrm{MeS}$ and control groups, explaining $4.9 \%$ and $6.7 \%$ of hsCRP variability, respectively (Table 3 ). However, when $25(\mathrm{OH}) \mathrm{D}$ was added to the independent variables, in the control group, two models were obtained. In model 1, again WC was the only predictor explaining $29.9 \%$ of hsCRP variability. In model 2, both WC and 25(OH)D were the predictors explaining $45.7 \%$ of the variability. In the MeS group there was only one model in which $25(\mathrm{OH}) \mathrm{D}$ was the main predictor of hsCRP explaining $8.4 \%$ of hsCRP variability (Table 4 ).

In another analysis performed to predict plasma glucose in both groups with $25(\mathrm{OH}) \mathrm{D}$, osteocalcin, hsCRP, BMI, WC and FM as independent variables, none of the variables entered the model in the control group. In the MeS group, however, only $25(\mathrm{OH}) \mathrm{D}$ entered the model, explaining $30.6 \%$ of plasma glucose variability $(P<0.001)$ (Table 5$)$.

\section{Discussion}

The occurrence rate of $28.3 \%$ of $\mathrm{MeS}$ in our subjects is noteworthy as only women with WC above $88 \mathrm{~cm}$, who were all overweight or obese, were examined for the criteria of MeS. Although women with MeS had higher BMI, WC and FM, this finding indicates that abdominal obesity as defined by 
Table 3 Stepwise multivariate linear regression analysis with hsCRP as dependent variable in the whole study population

\begin{tabular}{|c|c|c|c|c|c|c|}
\hline Group & Independent variables & B & SE & $\beta$ & $t$ & $P$-value \\
\hline & WC, FPG, HDL, TG, SBP and D & & & & & \\
\hline \multicolumn{7}{|l|}{ MeS } \\
\hline & Model I: WC & 0.074 & 0.034 & 0.221 & 2.188 & 0.031 \\
\hline \multicolumn{7}{|l|}{ Control } \\
\hline & Model I: WC & 0.064 & 0.025 & 0.259 & 2.581 & 0.011 \\
\hline & $\begin{array}{l}\text { WC, FPG, HDL, TG, SBP, DBP } \\
\text { and } 25(\mathrm{OH}) \mathrm{D}\end{array}$ & & & & & \\
\hline \multicolumn{7}{|l|}{ MeS } \\
\hline & Model I: 25(OH)D & -0.059 & 0.029 & -0.289 & -2.048 & 0.046 \\
\hline \multicolumn{7}{|l|}{ Control } \\
\hline & Model I: WC & 0.130 & 0.036 & 0.547 & 3.640 & 0.001 \\
\hline & Model 2: 25(OH)D & -0.059 & 0.020 & -0.400 & -2.946 & 0.006 \\
\hline & WC & 0.142 & 0.032 & 0.601 & 4.426 & $<0.001$ \\
\hline
\end{tabular}

Abbreviations: 25(OH)D, 25-hydroxyvitamin D; DBP, diastolic blood pressure; FPG, fasting plasma glucose; HDL-C, high-density lipoprotein cholesterol; hsCRP, highly sensitive C-reactive protein; LDL-C, low-density lipoprotein cholesterol; TG, triglycerides; WC, waist circumference.

NCEP/ATP III, ${ }^{1}$ despite its pivotal role, is not sufficient for development of MeS. Adipose tissue dysfunction may be more relevant to insulin resistance and other metabolic changes observed in MeS than the amount of fat mass itself. ${ }^{34}$ In support of this notion, it has been reported that in young South Asian men, insulin resistance could be present even in the absence of increased intraperitoneal fat and this might be due to the large size and dysfunction of subcutaneous abdominal adipocytes. ${ }^{35}$ More work is needed to elucidate the role of adipose tissue cellularity and function in MeS development.

High occurrence of vitamin D deficiency and insufficiency in both groups of women with and without $\mathrm{MeS}(86 \%$ and $89 \%$, respectively) is quite noticeable. Poor vitamin D status in obesity has already been reported. ${ }^{36}$ It is believed that extra body fat, by sequestrating vitamin $\mathrm{D}$, may reduce its bioavailability. ${ }^{7}$ The reasons for this high prevalence could be many: including blood sampling during the cold season; the high latitude of Tehran; air pollution; very inefficient direct sun exposure; and the fact that there is no vitamin D fortification program ongoing in Iran at this time. Moreover, according to the Islamic regulations, women must be veiled so that only face and hands (from wrist to the fingers) are allowed to be exposed. This may also contribute to the high occurrence of poor vitamin D status in our subjects.

The link between vitamin D status and metabolic syndrome has been, and still is, under debate. ${ }^{11,37}$ We found no difference in circulating $25(\mathrm{OH}) \mathrm{D}$ concentrations or vitamin D status between women with and without MeS. However, lower vitamin D status was accompanied by higher glucose concentrations and $25(\mathrm{OH}) \mathrm{D}$ was found to be the predictor of plasma glucose only in women with MeS. The relationship between vitamin $\mathrm{D}$ and glycemic status has been studied in both diabetic and nondiabetic subjects. ${ }^{38,39}$ In a recent clinical trial, vitamin D replenishment has led to the improvement of glycemic status in the subjects with T2D. ${ }^{40}$ Some evidence indicates that $1,25(\mathrm{OH}) 2 \mathrm{D}$, the active form of vitamin $\mathrm{D}$, can boost insulin secretion by enhancing calcium flux in pancreatic beta cells. ${ }^{41}$ An in vitro study showed that $1,25(\mathrm{OH}) 2 \mathrm{D}$ can induce the expression of insulin receptor and insulin responsiveness in U-937 human promonocytic cells. ${ }^{42}$

In the current study, serum $25(\mathrm{OH}) \mathrm{D}$ was not associated with lipid profile, WC, WHR, and BMI. Unlike this finding,

Table 4 Stepwise multivariate linear regression analysis with hsCRP as dependent variable

\begin{tabular}{|c|c|c|c|c|c|c|}
\hline Group & Independent variables & B & SE & $\beta$ & $t$ & $P$-value \\
\hline & WC, HDL, FPG, SBP, DBP & & & & & \\
\hline & and $25(\mathrm{OH}) \mathrm{D}$ & & & & & \\
\hline \multicolumn{7}{|l|}{ MeS } \\
\hline & Model I: 25(OH)D & -0.059 & 0.029 & -0.289 & -2.048 & 0.046 \\
\hline \multicolumn{7}{|l|}{ Control } \\
\hline & Model I: WC & 0.130 & 0.036 & 0.547 & 3.640 & 0.001 \\
\hline & Model 2: 25(OH)D & -0.059 & 0.020 & -0.400 & -2.946 & 0.006 \\
\hline & WC & 0.142 & 0.032 & 0.601 & 4.426 & $<0.001$ \\
\hline
\end{tabular}

Abbreviations: DBP, diastolic blood pressure; FPG, fasting plasma glucose; HDL-C, high-density lipoprotein cholesterol; hsCRP, highly sensitive C-reactive protein; LDL-C, low-density lipoprotein cholesterol; TG, triglycerides; WC, waist circumference; 25(OH)D, 25-hydroxyvitamin D. 
Table 5 Stepwise multivariate linear regression analysis with plasma glucose as dependent variable in women with MeS

\begin{tabular}{llllll}
\hline $\begin{array}{l}\text { Independent } \\
\text { variables }\end{array}$ & B & SE & $\beta$ & $t$ & $P$-value \\
\hline WC, BMI, FM, & & & & & \\
hsCRP, OST & & & & & \\
and 25(OH)D & & & & & \\
\begin{tabular}{l} 
Model I: 25(OH)D \\
\hline
\end{tabular} & -0.399 & 0.100 & -0.553 & -3.984 & $<0.001$ \\
\hline
\end{tabular}

Abbreviations: BMI, body mass index; FM, fat mass; hsCRP, highly sensitive C-reactive protein; OST, osteocalcin; WC, waist circumference; $25(\mathrm{OH}) \mathrm{D}$, 25-hydroxyvitamin.

the association of vitamin D status with some components of MeS such as serum HDL and triglycerides has been reported. ${ }^{43}$ Data from the Third National Health and Nutrition Examination Survey (NHANESIII) showed an inverse association between 25(OH)D and MeS. ${ }^{44}$ In a study performed on 1017 morbidly obese subjects (68\% female), parathyroid hormone (PTH) was identified as the predictor of MeS, even though no relationship between serum 25(OH)D and MeS was observed. ${ }^{45}$

Circulating 25(OH)D has been inversely associated with MeS in 1654 American adults independent of calcium intake and PTH, which were positively associated with MeS in older men. ${ }^{46}$ Other studies, however, have failed to show any contribution of vitamin D status in MeS. ${ }^{47-49}$ In a cross-sectional study on 542 Arab Americans, only men showed an association between vitamin D deficiency and components of $\mathrm{MeS}^{50}$ and there was no such association in Asian Indians at all. ${ }^{49} \mathrm{In}$ the latter study, the prevalence of MeS in 441 Asian Indians, comprising 237 men and 204 women, was $27.9 \%$ and the occurrence of vitamin D insufficiency, defined as $25(\mathrm{OH})$ $\mathrm{D}<50 \mathrm{nmol} / \mathrm{L}$, was $65.5 \%$ with no gender difference. ${ }^{49}$ The discrepancies seen in the results of studies may be due to the different study populations, the seasons of the studies and the methods used for determination of $25(\mathrm{OH}) \mathrm{D}$. The very high occurrence of vitamin $\mathrm{D}$ deficiency in our subjects could be due to blood sampling during cold seasons, when dermal synthesis of vitamin D is negligible. Moreover, it has been demonstrated that both radioimmunoassay (RIA) and competitive proteinbinding assay (CPBA) may overestimate circulating 25(OH)D, compared to the HPLC method, ${ }^{31}$ that was used in this study.

The significantly lower serum concentrations of osteocalcin in women with MeS compared to the control group was of great importance. Lower serum osteocalcin concentrations in MeS have also been reported in other studies. ${ }^{14,15,51,52}$ Increased risk of MeS, independent of serum glucose, has been observed in Korean men and women who were in the lower quartiles (Q1-Q3) of serum osteocalcin, compared to those in the highest quartile. ${ }^{14}$
An MeS-related pro-inflammatory state seems to have a determining role in the further morbidities ascribed to $\mathrm{MeS}$, including diabete ${ }^{53}$ and cardiovascular disease (CVD) ${ }^{54}$

Assuming truncal fat being the core feature of MeS, ${ }^{2}$ the other components, notably inflammation, may emanate from the abdominal excess fat. ${ }^{55}$ However, significantly higher serum hsCRP in our subjects with MeS compared to the control group even after controlling for WC and FM indicates that systemic inflammation often accompanied by obesity may not originate solely from the adipose tissue. Lower inflammatory status, as judged by serum concentrations of CRP, has been suggested to have a protective role in the so-called "metabolically healthy but obese" phenotype against such comorbidities as cardiovascular disease (CVD) ${ }^{56}$ It has been hypothesized that chronic inflammatory stimuli together with diminished anti-inflammatory mechanisms may have a role in metabolic derangements and endothelial dysfunction in MeS. ${ }^{57,58}$ Dietary pattern may also contribute to the inflammatory process. Higher intakes of fruits and vegetables, which are rich in anti-inflammatory antioxidants, were inversely associated with serum levels of CRP and development of MeS, ${ }^{59}$ while red meat ${ }^{60}$ high fat dairy products ${ }^{61}$ and hydrogenated oil ${ }^{62}$ consumption was associated with higher circulating inflammatory biomarkers and greater risk of MeS.

An inverse association between serum 25(OH)D and hsCRP may support the suggestion of an anti-inflammatory function of vitamin D. Though we found no significant difference in vitamin $\mathrm{D}$ status between women with and without $\mathrm{MeS}, 25(\mathrm{OH}) \mathrm{D}$ was the only predictor of both hsCRP and plasma glucose in the subjects with MeS.

Considering the anti-inflammatory effects of cholecalciferol, ${ }^{63}$ poor vitamin D status may contribute to the systemic inflammation often seen in obesity, thus favoring other metabolic derangements like insulin resistance and raised blood glucose. The possible anti-inflammatory effects of vitamin D must be evaluated in the controlled clinical trials. ${ }^{64}$

This study had some limitations. Blood samples were drawn during the cold seasons, when dermal synthesis of vitamin $\mathrm{D}$ is minimal, so the vitamin D status of our subjects did not necessarily reflect their status for the whole year. Because of the high proportion of vitamin D deficiency in both groups, it was difficult to show the differences, if any. Moreover, only women were enrolled in the study. Therefore the relationship between vitamin D status and MeS in men remains to be studied.

In conclusion, various degrees of vitamin D deficiency had more than $85 \%$ prevalence among overweight/obese middle-aged women in Tehran who participated in this study. Although there was no significant difference in either 
serum $25(\mathrm{OH}) \mathrm{D}$ or vitamin $\mathrm{D}$ status between women with and without MeS, 25(OH)D was a predictor of hsCRP, the biomarker of systemic inflammation, in women with MeS but not in the controls. Thus, vitamin D status may, at least in part, be a determining factor of systemic inflammation and the related metabolic derangements of MeS.

\section{Acknowledgments}

This study was funded by the National Nutrition and Food Technology Research Institute (NNFTRI). All laboratory works were performed at the Laboratory of Nutrition Research, NNFTRI. The study was designed and supervised by Dr Tirang R Neyestani. Ms Shabnam Salekzamani was fully involved in both field and laboratory work this study, which was part of her MSc thesis. Statistical analyses were performed under the directions of Dr Hamid Alavi-Majd with the aid of Dr Bahareh Nikooyeh. We also thank Mr Ali Kalayi, Mrs Nastaran Shariatzadeh and Mrs A'azam Gharavi, the laboratory staff, for their sincere cooperation in both laboratory and field work. We also thank Dr Simin Vaghefi for refining the manuscript language. Finally, we do appreciate all the subjects who devotedly participated in this study.

\section{Disclosure}

The authors declare no conflicts of interest.

\section{References}

1. Third Report of the National Cholesterol Education Program (NCEP) expert panel on detection, evaluation, and treatment of high blood cholesterol in adults (Adult Treatment Panel III) final report. Circulation. 2002;106(25):3143-3421.

2. Despres JP, Lemieux I, Bergeron J, et al. Abdominal obesity and the metabolic syndrome: contribution to global cardiometabolic risk Arterioscler Thromb Vasc Biol. 2008;28(6):1039-1049.

3. Elks CM, Francis J. Central adiposity, systemic inflammation, and the metabolic syndrome. Curr Hypertens Rep. 2010;12(2):99-104.

4. Kressel G, Trunz B, Bub A, et al. Systemic and vascular markers of inflammation in relation to metabolic syndrome and insulin resistance in adults with elevated atherosclerosis risk. Atherosclerosis. 2009; 202(1):263-271.

5. Neyestani TR, Salekzamani S, Kalayi A, et al. Predictors of serum levels of high sensitivity C-reactive protein and systolic blood pressure in overweight and obese nondiabetic women in Tehran: a cross-sectional study. Metab Syndr Relat Disord. 2011;9(1):41-47.

6. Manolopoulos KN, Karpe F, Frayn KN. Gluteofemoral body fat as a determinant of metabolic health. Int J Obes (Lond). 2010;34(6): 949-959.

7. Wortsman J, Matsuoka LY, Chen TC, Lu Z, Holick MF. Decreased bioavailability of vitamin D in obesity. Am J Clin Nutr. 2000;72(3): 690-693.

8. Boucher BJ. Inadequate vitamin D status: does it contribute to the disorders comprising syndrome "X"? Br J Nutr. 1998;79(4):315-327.

9. Chiu KC, Chu A, Go VL, Saad MF. Hypovitaminosis D is associated with insulin resistance and beta cell dysfunction. Am J Clin Nutr. 2004; 79(5):820-825.

10. Liu S, Song Y, Ford ES, Manson JE, Buring JE, Ridker PM. Dietary calcium, vitamin D, and the prevalence of metabolic syndrome in middleaged and older US women. Diabetes Care. 2005;28(12):2926-2932.
11. Florentin M, Elisaf MS, Mikhailidis DP, Liberopoulos EN. Vitamin D and metabolic syndrome: is there a link? Curr Pharm Des. 2010; 16(30):3417-3434.

12. Kayaniyil S, Vieth R, Harris SB, et al. Association of $25(\mathrm{OH}) \mathrm{D}$ and PTH with metabolic syndrome and its traditional and nontraditional components. J Clin Endocrinol Metab. 2011;96(1):168-175.

13. Skjodt H, Gallagher JA, Beresford JN, Couch M, Poser JW, Russell RG. Vitamin D metabolites regulate osteocalcin synthesis and proliferation of human bone cells in vitro. J Endocrinol. 1985;105(3):391-396.

14. Bae SJ, Choe JW, Chung YE, et al. The association between serum osteocalcin levels and metabolic syndrome in Koreans. Osteoporos Int. December 9, 2010. [Epub ahead of print].

15. Saleem U, Mosley TH Jr, Kullo IJ. Serum osteocalcin is associated with measures of insulin resistance, adipokine levels, and the presence of metabolic syndrome. Arterioscler Thromb Vasc Biol. 2010;30(7): $1474-1478$.

16. Guillot X, Semerano L, Saidenberg-Kermanac'h N, Falgarone G, Boissier MC. Vitamin D and inflammation. Joint Bone Spine. 2010; 77(6):552-557.

17. Cancello R, Clement K. Is obesity an inflammatory illness? Role of low-grade inflammation and macrophage infiltration in human white adipose tissue. BJOG. 2006;113(10):1141-1147.

18. Amiri F. Metabolic syndrome, insulin resistance and oxidative stress: adding insights to improve cardiovascular prevention. $J$ Hypertens. 2009;27(7):1352-1354.

19. Pischon T, Hu FB, Rexrode KM, Girman JC, Manson AE, Rimm EB. Inflammation, the metabolic syndrome, and risk of coronary heart disease in women and men. Atherosclerosis. 2008;197(1):392-399.

20. Barbarroja N, Lopez-Pedrera R, Mayas MD, et al. The obese healthy paradox: is inflammation the answer? Biochem J. 2010;430(1):141-149.

21. Jablonski KL, Chonchol M, Pierce GL, Walker AE, Seals DR. 25-Hydroxyvitamin D deficiency is associated with inflammationlinked vascular endothelial dysfunction in middle-aged and older adults. Hypertension. 2011;57(1):63-69.

22. Yiu YF, Chan YH, Yiu KH, et al. Vitamin D deficiency is associated with depletion of circulating endothelial progenitor cells and endothelial dysfunction in patients with type 2 diabetes. J Clin Endocrinol Metab. 2011;96(5):E830-E835.

23. Peng X, Vaishnav A, Murillo G, Alimirah F, Torres KE, Mehta RG. Protection against cellular stress by 25 -hydroxy vitamin D3 in breast epithelial cells. J Cell Biochem. 2010;110(6):1324-1333.

24. Sun X, MB. Z. 1alpha,25-dihydroxyvitamin D3 modulation of adipocyte reactive oxygen species production. Obesity. 2007;15(8):1944-1953.

25. Kelishadi R, Gharipour M, Sadri GH, Tavasoli AA, Amani A. Cardiovascular disease risk factors, metabolic syndrome and obesity in an Iranian population. East Mediterr Health J. 2008;14(5):1070-1079.

26. Brustad MAE, Engelsen O, Aksnes L, Lund E. Vitamin D status of middle-aged women at 65-71 degrees $\mathrm{N}$ in relation to dietary intake and exposure to ultraviolet radiation. Public Health Nutr. 2003;7(2): 327-334.

27. Matthews DR, JP. H. Homeostasis model assessment: insulin resistance and beta-cell function from fasting plasma glucose and insulin concentration in man. Diabetologia. 1985;28(7):412-419.

28. Satoh K. Serum lipid peroxide in cerebrovascular disorders determined by a new colorimetric method. Clin Chim Acta. 1978;90(1):37-43.

29. Neyestani TR, Shariatzadeh A, Gharavi A, Kalayi A, Khalaj N. Physiological dose of lycopene suppressed oxidative stress and enhanced serum levels of immunoglobolin $\mathrm{M}$ in patients with type 2 diabetes mellitus: a possible role in the prevention of long-term complications. J Endocrinol Invest. 2007;30(10):833-938.

30. Neyestani TR, Fereydouni Z, Hejazi S, et al. Vitamin C status in Iranian children with acute lymphoblastic leukemia: evidence for increased utilization. J Pediatr Gastroenterol Nutr. 2007;45(1):141-144.

31. Neyestani TR, Gharavi A, Kalayi A. Determination of serum 25-hydroxy cholecalciferol using high-performance liquid chromatography: a reliable tool for assessment of vitamin D status. Int J Vitam Nutr Res. 2007;77(5):341-346. 
32. Saintonge S, Bang H, Gerber LM. Implications of a new definition of vitamin D deficiency in a multiracial US adolescent population: the National Health and Nutrition Examination Survey (III). Pediatrics. 2009;123(3):797-803.

33. Hsu CS, Liu CJ, Liu CH, et al. High hepatitis C viral load is associated with insulin resistance in patients with chronic hepatitis C. Liver Int. 2008;28(2):271-277.

34. Chandalia M, Abate N. Metabolic complications of obesity: inflated or inflamed? J Diabetes Complications. 2007;21(2):128-136.

35. Chandalia M, Lin P, Seenivasan $\mathrm{T}$, et al. Insulin resistance and body fat distribution in South Asian men compared to Caucasian men. PLoS One. 2007;2(8):e812.

36. Aasheim ET, Hofso D, Hjelmeseth J, Birkeland KI, Bohmer T. Vitamin status in morbidly obese patients: a cross-sectional study. Am J Clin Nutr. 2008;87(2):362-369.

37. Boucher B. Inadequate vitamin D status: does it contribute to the disorders comprising syndrome "X". Br J Nutr. 1998;79(4):315-327.

38. Patel P, Poretsky L, Liao E. Lack of effect of subtherapeutic vitamin D treatment on glycemic and lipid parameters in type 2 diabetes: a pilot prospective randomized trial. Journal of Diabetes. 2010;2(1):36-40.

39. Pittas AG HSS, Stark PC, Dawson-Hughes B. The effects of calcium and vitamin D supplementation on blood glucose and markers of inflammation in nondiabetic adults. Diabetes Care. 2007;30(4): 980-986.

40. Nikooyeh B, Neyestani TR, Farvid M, et al. Daily consumption of vitamin D- or vitamin D+ calcium-fortified yogurt drink improved glycemic control in patients with type 2 diabetes: a randomized clinical trial. Am J Clin Nutr. 2011;93(4):764-771.

41. Bourlon P, Billaudel B, Faure-Dussert A. Influence of vitamin D3 deficiency and 1,25 dihydroxyvitamin D3 on de novo insulin biosynthesis in the islets of the rat endocrine pancreas. J Endocrinol. 1999; 160(1):87-95.

42. Maestro B CJ, Davila N, Calle C. Stimulation by 1,25-dihydroxyvitamin D3 of insulin receptor expression and insulin responsiveness for glucose transport in U-937 human promonocytic cells. Endocr J. 2000;47(4): 383-391.

43. McGill AT, Stewart JM, Lithander FE, Strik CM, Poppitt SD. Relationships of low serum vitamin D3 with anthropometry and markers of the metabolic syndrome and diabetes in overweight and obesity. Nutr J. 2008;7:4.

44. Ford ES, Ajani UA, McGuire LC, Liu S. Concentrations of serum vitamin D and the metabolic syndrome among US adults. Diabetes Care. 2005;28(5):1228-1230.

45. Hjelmesæth J, Hofsø D, Aasheim ET, et al. Parathyroid hormone, but not vitamin D, is associated with the metabolic syndrome in morbidly obese women and men: a cross-sectional study. Cardiovasc Diabetol. 2009;8:7.

46. Reis JP, von Muhlen D, Miller ER 3rd. Relation of 25-hydroxyvitamin $\mathrm{D}$ and parathyroid hormone levels with metabolic syndrome among US adults. Eur J Endocrinol. 2008;159(1):41-48.

47. Rueda S, Fernández-Fernández C, Romero F, Osaba MJ, Vidal J. Vitamin D, PTH, and the metabolic syndrome in severely obese subjects. Obes Surg. 2008;18(2):151-154.
48. Reis JP, von Muhlen D, Kritz-Silverstein D, Wingard DL, Barrett-Connor E. Vitamin D, parathyroid hormone levels, and the prevalence of metabolic syndrome in community-dwelling older adults. Diabetes Care. 2007;30(6):1549-1555.

49. Majumdar V, Nagaraja D, Christopher R. Vitamin D status and metabolic syndrome in Asian Indians. Int J Obes (Lond). November 9, 2010. [Epub ahead of print].

50. Pinelli NR, Jaber LA, Brown MB, Herman WH. Serum 25-hydroxy vitamin $\mathrm{D}$ and insulin resistance, metabolic syndrome, and glucose intolerance among Arab Americans. Diabetes Care. 2010;33(6): 1373-1375.

51. Yeap BB, Chubb SA, Flicker L, et al. Reduced serum total osteocalcin is associated with metabolic syndrome in older men via waist circumference, hyperglycemia, and triglyceride levels. Eur J Endocrinol. 2010; 163(2):265-272.

52. Tan A, Gao Y, Yang X, et al. Low serum osteocalcin level is a potential marker for metabolic syndrome: results from a Chinese male population survey. Metabolism. February 23, 2010. doi: 10.1016/j.metabol.2011.01.002.

53. Blaha MJ, Gebretsadik T, Shintani A, Elasy TA. Waist circumference, not the metabolic syndrome, predicts glucose deterioration in type 2 diabetes. Obesity (Silver Spring). 2008;16(4):869-874.

54. Berg AH, Scherer PE. Adipose tissue, inflammation, and cardiovascular disease. Circ Res. 2005;96(9):939-949.

55. Fontana L, Eagon JC, Trujillo ME, Scherer PE, Klein S. Visceral fat adipokine secretion is associated with systemic inflammation in obese humans. Diabetes. 2007;56(4):1010-1013.

56. Karelis AD, Faraj M, Bastard JP, et al. The metabolically healthy but obese individual presents a favorable inflammation profile. $J$ Clin Endocrinol Metab. 2005;90(7):4145-4150.

57. Esposito K, Giugliano D. The metabolic syndrome and inflammation: association or causation? Nutr Metab Cardiovasc Dis. 2004;14(5): 228-232.

58. Kloting N, Fasshauer M, Dietrich A, et al. Insulin-sensitive obesity. Am J Physiol Endocrinol Metab. 2010;299(3):E506-E515.

59. Esmaillzadeh A, Kimiagar M, Mehrabi Y, Azadbakht L, Hu FB, Willett WC. Fruit and vegetable intakes, C-reactive protein, and the metabolic syndrome. Am J Clin Nutr. 2006;84(6):1489-1497.

60. Azadbakht L, Esmaillzadeh A. Red meat intake is associated with metabolic syndrome and the plasma C-reactive protein concentration in women. $J$ Nutr. 2009;139(2):335-339.

61. Esmaillzadeh A, Azadbakht L. Dairy consumption and circulating levels of inflammatory markers among Iranian women. Public Health Nutr. 2010;13(9):1395-1402.

62. Esmaillzadeh A, Azadbakht L. Consumption of hydrogenated versus nonhydrogenated vegetable oils and risk of insulin resistance and the metabolic syndrome among Iranian adult women. Diabetes Care. 2008;31(2):223-226.

63. Krishnan AV, Feldman D. Mechanisms of the anti-cancer and antiinflammatory actions of vitamin D. Annu Rev Pharmacol Toxicol. 2011;51:311-336.

64. Hoeck AD, Pall ML. Will vitamin D supplementation ameliorate diseases characterized by chronic inflammation and fatigue? Med Hypotheses. 2011;76(2):208-213.

Diabetes, Metabolic Syndrome and Obesity: Targets and Therapy

Dovepress

\section{Publish your work in this journal}

Diabetes, Metabolic Syndrome and Obesity: Targets and Therapy is an international, peer-reviewed open-access journal committed to the rapid publication of the latest laboratory and clinical findings in the fields of diabetes, metabolic syndrome and obesity research. Original research, review, case reports, hypothesis formation, expert opinion and commentaries are all considered for publication. The manuscript management system is completely online and includes a very quick and fair peer-review system, which is all easy to use. Visit http://www.dovepress.com/testimonials.php to read real quotes from published authors. 